\title{
Neurosurgical sequelae of domestic dog attacks in children
}

\author{
Ramesh Kumar, MD, ${ }^{1}$ Frederic W. B. Deleyiannis, MD, MPhil, MPH, ${ }^{3}$ Corbett Wilkinson, MD, ${ }^{1,2}$ and \\ Brent R. O'Neill, MD',2
}

\begin{abstract}
'Department of Neurosurgery, University of Colorado; '2Department of Neurosurgery, Children's Hospital Colorado; and ${ }^{3}$ Department of Plastic Surgery, University of Colorado, Aurora, Colorado
\end{abstract}

\begin{abstract}
OBJECTIVE The authors' goals in this study were to describe a series of dog attacks on children that required neurosurgical consultation and to better understand the pattern of injuries inflicted, the circumstances that place children at risk for attack, and the dog breeds involved. In addition, the authors review the surgical and medical management of these patients.
\end{abstract}

METHODS The authors performed a retrospective review of all children requiring neurosurgical consultation for dog bite at a regional Level 1 pediatric trauma center over a 15-year period.

RESULTS A total of 124 children with dog bites to the head, face, and neck were evaluated in the emergency department. Of these, 17 children (13.7\%) incurred injuries requiring neurosurgical consultation. Fifty-three percent of victims were female. The mean age at the time of attack was 30 months. Twelve $(71 \%)$ of the attacks were perpetrated by the family pet, and $13(76 \%)$ occurred at the patient's home. Breeds involved in the attacks included German Shepherd, Pit Bull, American Bulldog, large mixed breed, Labrador Retriever, and Akita, with German Shepherds and Akitas being the most frequently involved. Neurosurgical injuries included nondepressed skull fracture in 5 , depressed skull fracture in 10 , intracranial hemorrhage in 5, cerebral contusions in 4, dural laceration in 4, pneumocephalus in 5 , clinically evident CSF leak in 3 , spinal fracture with complete spinal cord injury in 1 , stroke in 2 , vascular injury in 2 , and cranial nerve injury (hypoglossal and facial nerve) in 1. Prophylactic antibiotics were administered in 16 patients (94\%). Only 1 patient had a confirmed infection involving the site of injury. Neurosurgical intervention was required in 10 patients (59\%) and ranged in severity from debridement and closure of a complex scalp wound to decompressive craniectomy. Neurological deficits, all of which were considered catastrophic, developed in 3 patients (18\%).

CONCLUSIONS Dog attacks on children requiring neurosurgical consultation commonly involve the family pet, which is usually a large-breed dog with no history of prior aggression. Neurosurgical injuries often involve the cranial vault, with depressed skull fractures being the most common injury pattern. Most patients do not suffer a neurological deficit, although catastrophic neurological injury may occur. Prophylactic antibiotics are commonly used and surgical intervention is required in the majority of cases.

http://thejns.org/doi/abs/10.3171/2016.7.PEDS1646

KEY WORDS dog bite; intracranial injury; neurosurgical injury; animal bite; trauma

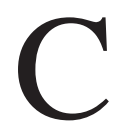

ANINES have played an important role in the history of modern humans, providing companionship, security, and labor. However, this relationship can at times be strained, as evident by the considerable public health problem of domestic dog attacks, especially among the pediatric population. In 2001 alone, 368,245 patients were treated in US emergency departments for dog bites, the majority of whom were 5-9 years old.$^{3}$ Dog attacks on children may cause significant morbidity ${ }^{2,6}$ and occasionally may even be fatal. ${ }^{2,21,26}$

Attacks on young children are often focused on the head and neck region, ${ }^{4,9,26}$ likely given the small stature of the child and the dogs' instinctual propensity to target vital structures. According to the National Electronic Injury Surveillance System, $64.9 \%$ of all dog bite injuries in children $0-4$ years old occurred to the head and neck region. ${ }^{3}$ Despite this predilection for injuries to the head and neck, there is a paucity of published literature on dog attacks that require neurosurgical intervention. The objective of this study is to describe a series of dog attacks on children that required neurosurgical consultation, to better understand the pattern of injuries and dog breeds involved, to identify 
potential commonalities that may place children at risk, and to review the surgical and medical management of these patients.

\section{Methods}

We performed a retrospective review of all children who were admitted through the emergency department at a regional Level 1 pediatric trauma center from January 1 , 2000 , through the end of 2015. All children who incurred an injury requiring a neurosurgical consultation were included in the study. Children with injuries to the scalp, without documented trauma to the cranial vault, were excluded from review. This study protocol was approved by the Colorado Multiple Institutional Review Board.

\section{Results}

A total of 124 children were evaluated for dog bites to the head, face, and neck. Seventeen (13.7\%) of these children incurred injuries requiring neurosurgical consultation.

In this subset of 17 patients, 9 females (53\%) and 8 males (47\%) were victims of a dog attack (Table 1). Age at the time of attack ranged from 6 to 125 months with a mean age of 30 months. Eight attacks occurred in an urban area and 9 in a rural location. Thirteen (76\%) of the attacks took place at the patient's home. The breeds involved in the attacks were as follows: German Shepherd $(\mathrm{n}=3)$, Akita $(\mathrm{n}=3)$, Pit Bull $(\mathrm{n}=2)$, American Bulldog ( $=2)$, Labrador Retriever $(n=2)$, large mixed breed $(n=2)$, Great Dane $(\mathrm{n}=1)$, Rottweiler $(\mathrm{n}=1)$, and unknown breed $(n=1)$. Twelve $(71 \%)$ of the dogs were family pets, $2(12 \%)$ were a friend's/neighbor's pet, and $3(18 \%)$ dogs were unknown to the victims. All attacks were unprovoked. Only one of the dogs was known to be involved in a previous attack, which was against the patient's sibling on the same day. Otherwise, no dogs were noted to have shown previous signs of aggression.

Sixteen patients $(94 \%)$ were admitted to the hospital after the attack, and 1 patient was discharged directly from the emergency department. Of those patients admitted to the hospital, 5 were to the intensive care unit and 10 to the neurosurgical ward; documentation was lacking in 1 case. Hospital length of stay ranged from 2 to 143 days with a median stay of 3 days. Neurosurgical injuries included nondepressed skull fracture in 5 patients, depressed skull fracture in 10 , intracranial hemorrhage in 5, cerebral contusions in 4, dural laceration in 4, pneumocephalus in 5, clinically evident CSF leakage in 3, spinal fracture with complete spinal cord injury (SCI) in 1, stroke in 2 , vascular injury in 2 , and cranial nerve injury (hypoglossal and facial nerve) in 1 . The 2 cases of stroke were secondary to direct injury to the $\mathrm{M}_{3}$ and $\mathrm{M}_{4}$ branches of the middle cerebral artery in one case and from complete occlusion of the cervical internal carotid artery (ICA) due to traumatic dissection in the other (both cases detailed below). Of the children who were found to have intracranial hemorrhage, 5 had traumatic subarachnoid hemorrhage, 3 had intraparenchymal hemorrhage, 1 had a subdural hematoma, and 1 had intraventricular hemorrhage. Eight patients had concomitant injuries to the eyes,
TABLE 1. Patient demographics and characteristics of attack

\begin{tabular}{|c|c|}
\hline Variable & Value \\
\hline No. of patients & 17 \\
\hline Male & $8(47 \%)$ \\
\hline Female & $9(53 \%)$ \\
\hline Mean age (range) in mos & $30(6-125)$ \\
\hline \multicolumn{2}{|l|}{ Dog breed } \\
\hline German Shepherd & 3 \\
\hline Akita & 3 \\
\hline Pit Bull & 2 \\
\hline American Bulldog & 2 \\
\hline Great Dane & 1 \\
\hline Labrador Retriever & 2 \\
\hline Rottweiler & 1 \\
\hline Mixed breed & 2 \\
\hline Unknown breed & 1 \\
\hline \multicolumn{2}{|l|}{ Familiarity w/ dog } \\
\hline Family pet & 12 \\
\hline Friend's/neighbor's pet & 2 \\
\hline Unknown to victim & 3 \\
\hline \multicolumn{2}{|l|}{ Injury } \\
\hline DSF & 10 \\
\hline NDSF & 5 \\
\hline $\mathrm{ICH}$ & 5 \\
\hline Dural laceration & 4 \\
\hline Pneumocephalus & 5 \\
\hline CSF leak & 3 \\
\hline Spinal fracture/SCI & 1 \\
\hline Vascular injury w/ stroke & 2 \\
\hline Cerebral contusion & 4 \\
\hline CN injury & 1 \\
\hline
\end{tabular}

$\mathrm{CN}=$ cranial nerve; $\mathrm{DSF}=$ depressed skull fracture; $\mathrm{ICH}$ = intracranial hemorrhage; NDSF = nondepressed skull fracture.

ears, or face, 2 patients had remote injuries (one patient with multiple rib fractures causing flail chest and another with deep lacerations to the back and arms), and 1 patient had injuries to the neck.

Surgical intervention was required in 12 patients (71\%). A total of 22 neurosurgical procedures were performed in 10 patients (59\%). Eight patients (47\%) underwent a single neurosurgical intervention, while 1 patient (Case 5) required 3 neurosurgical procedures (CSF drainage via lumbar drain, posterior spinal fusion, and intrathecal baclofen pump placement), and the remaining patient (Case 11) underwent multiple neurosurgical procedures (11 procedures in 8 separate settings). Eight patients required other surgical procedures including laceration repair, parotid gland exploration, rib plating, tracheostomy, percutaneous endoscopic gastrostomy, and plastic surgery. Neurosurgical procedures included decompressive craniectomy $(n=1)$, external ventricular drainage $(\mathrm{n}=3$, all performed in Case $11)$, ventriculoperitoneal shunt placement $(n=1)$, ventriculoperitoneal shunt revision $(\mathrm{n}=1)$, intracranial pressure 
TABLE 2. Characteristics of 17 dog attacks requiring neurosurgical consultation

\begin{tabular}{|c|c|c|c|c|c|}
\hline Case No. & Age (mos), Sex & Dog Breed & Injury & Neurosurgical Procedure & Neurological Deficit \\
\hline 1 & $8, F$ & Rottweiler & NDSF & None & None \\
\hline $2^{*}$ & $58, \mathrm{M}$ & Unknown & $\begin{array}{l}\text { NDSF, ICH, stroke, vascular } \\
\text { injury, peripheral CN injury }\end{array}$ & Cervical ICA exploration & $\begin{array}{l}\text { Hemiparesis, cogni- } \\
\text { tive delay }\end{array}$ \\
\hline 3 & $21, \mathrm{~F}$ & Akita & DSF, dural tear & Elevation of DSF, dural repair & None \\
\hline 4 & $15, \mathrm{~F}$ & GS & DSF & Elevation of DSF & None \\
\hline $5^{*}$ & $38, F$ & Akita & CSF leak, SCI & Lumbar drain, PSF, baclofen pump & T-6 paraplegia \\
\hline 6 & $92, \mathrm{~F}$ & GD & NDSF & Exploration of skull fracture & None \\
\hline 7 & $14, \mathrm{M}$ & Labrador & DSF & None & None \\
\hline 8 & $11, \mathrm{M}$ & Akita & DSF & None & None \\
\hline 9 & $38, F$ & GS & NDSF & None & None \\
\hline 10 & $22, \mathrm{~F}$ & Pit Bull & DSF, contusion & None & None \\
\hline 11 & $9, M$ & $A B$ & $\begin{array}{l}\text { DSF, ICH, stroke, vascular } \\
\text { injury, CSF leak, contusion }\end{array}$ & $\begin{array}{l}\text { Decompressive craniectomy, ICP monitoring, EVD, } \\
\text { VP shunt placement, cranial wound washouts ( } 2)\end{array}$ & $\begin{array}{l}\text { Hemiparesis, cogni- } \\
\text { tive delay }\end{array}$ \\
\hline 12 & $125, M$ & Mixed & NDSF & Frontal sinus reduction/plating & None \\
\hline 13 & $6, F$ & Pit Bull & $\mathrm{ICH}$, dural tear, CSF leak & Scalp \& dural repair & None \\
\hline 14 & $6, M$ & $A B$ & $\mathrm{DSF}, \mathrm{ICH}$, contusion & Debridement \& scalp closure & None \\
\hline 15 & $12, \mathrm{~F}$ & GS & DSF, dural tear & None & None \\
\hline 16 & $28, M$ & Mixed & NDSF & None & None \\
\hline 17 & $8, M$ & Labrador & DSF, ICH, contusion & Elevation of DSF & None \\
\hline
\end{tabular}

$\mathrm{AB}=$ American Bulldog; $\mathrm{EVD}$ = external ventricular drain; $\mathrm{GD}=$ Great Dane; $\mathrm{GS}=$ German Shepherd; ICP = intracranial pressure; PSF = posterior spinal fusion; $\mathrm{VP}=$ ventriculoperitoneal.

* Previously described in a series by Calkins et al. ${ }^{2}$

monitoring $(\mathrm{n}=1)$, removal of intracranial packing material $(n=1)$, wound washout and debridement $(n=2$, both performed in Case 11), exploration of the cervical ICA (n $=1)$, elevation of depressed skull fracture $(\mathrm{n}=3)$, dural repair $(n=2)$, laceration repair with exploration of skull fracture $(n=1)$, lumbar drain placement for CSF leakage $(n=1)$, reduction and internal fixation of frontal sinus fracture $(n=1)$, posterior spinal fusion $(n=1)$, debridement and closure of complex scalp wound on top of a skull fracture $(\mathrm{n}=1)$, and placement of an intrathecal baclofen pump several years after SCI $(\mathrm{n}=1)$. No complications were directly attributed to surgical intervention. Two patients $(12 \%)$ required transfusion of blood products at the time of surgery. One patient (Case 11) experienced cardiac arrest at the time of decompressive craniectomy but was successfully resuscitated. Neurological deficits developed in 3 patients (18\%), all of which were catastrophic. These included hemiparesis and significant developmental delay in 2 patients and a T-6 level paraplegia secondary to complete spinal cord injury in another (Table 2).

Prophylactic antibiotics were administered in 16 patients (94\%), while status of administration was unknown in 1 case. All patients initially received intravenous antibiotics, with most being converted to an oral medication after 1-2 days. Three patients without definitive evidence of infection received a prolonged period ( $>3$ weeks) of intravenous antibiotics. All of these patients were younger than 12 months with evidence of dural penetration and injury involving the brain parenchyma, leading to a high level of concern for the development of central nervous system infection. One patient with extensive tissue loss of the scalp and skull (Case 11, detailed below) had confirmed infection involving the site of injury, detected on 2 separate occasions. The initial infection was detected within the 1st week with cultures positive for Klebsiella and Pseudomonas spp. The second infection was delayed, occurring approximately 3 months after the initial injury, and was caused by a fungal species, Scedosporium.

\section{Illustrative Cases}

Case 2

This 4-year-old boy (previously included in a study by Calkins et al. ${ }^{2}$ ) was riding his bike with his father in a rural area when he was attacked by a dog of unknown breed. He incurred several lacerations to the head, face, and neck. Initial evaluation in the emergency department revealed a nondisplaced left temporal bone fracture with associated pneumocephalus and subarachnoid hemorrhage and subcutaneous emphysema within the soft tissues of the neck. Initial CT scanning of the neck with contrast was read as negative for any vascular or cervical spine injury at the time; however, upon review of the imaging, we were able to detect a complete occlusion of the left cervical ICA. The patient underwent exploration and repair of the neck lacerations on the day of the injury, at which time no external injury to the cervical ICA was noted. He was admitted to the intensive care unit for close observation. The day after the attack he experienced a generalized tonic-clonic seizure, after which he developed a right hemiparesis. Cerebral angiography was performed that revealed occlusion of the left ICA and vertebral artery at the level of C2-3. 


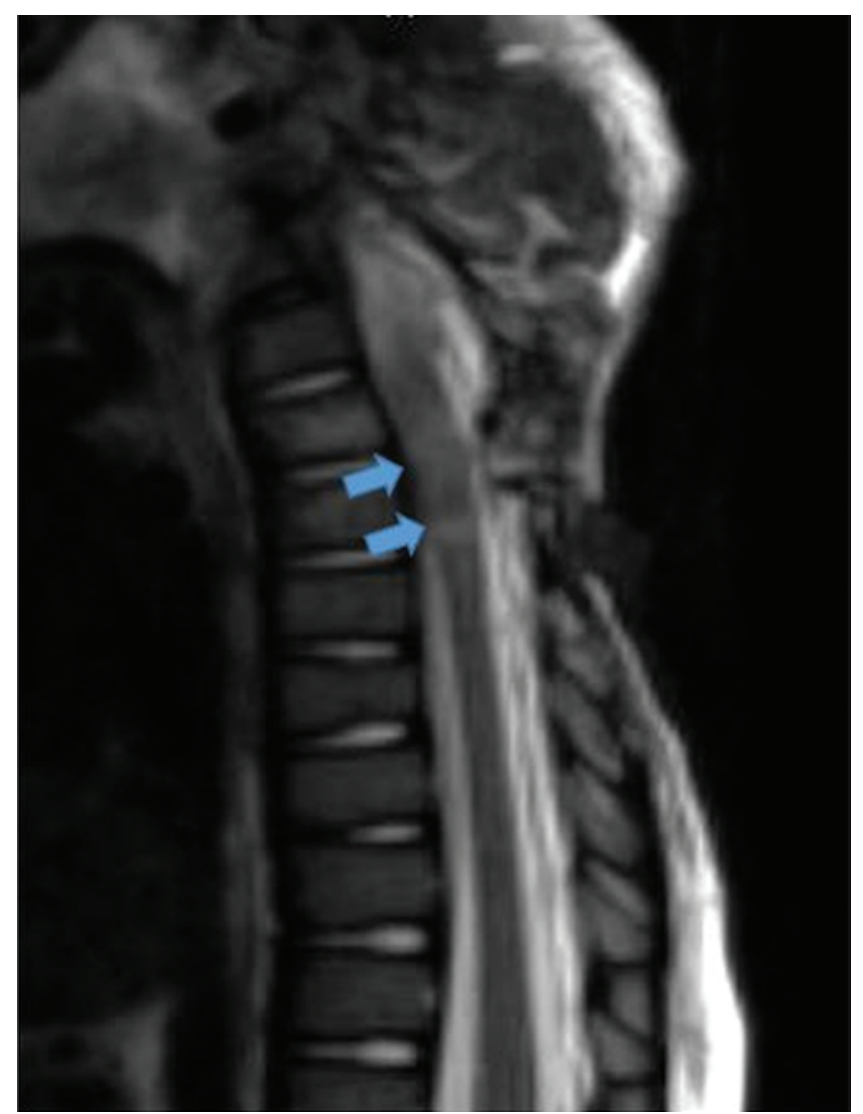

FIG. 1. Case 5. Sagittal T2-weighted MR image obtained in a 3-year-old girl attacked by the family Akita, showing tissue damage to the posterior vertebral column from T-4 to T-6 with corresponding T2 hyperintensity within the spinal cord (arrows), indicating injury to the neural tissue. Figure is available in color online only.

A CT scan of the head revealed a large area of infarction within the left middle cerebral artery territory. Anticoagulation was started immediately.

On further examination, the patient was noted to have absent function of the hypoglossal and facial nerves on the ipsilateral side of the attack. The patient subsequently had a prolonged hospitalization requiring tracheostomy and gastrostomy tube placement for respiratory and feeding difficulties, respectively. At the time of last follow-up, his hemiparesis had significantly improved, but he continues to have developmental delay.

\section{Case 5}

This 3-year-old girl (previously included in a study by Calkins et al. ${ }^{2}$ ) was in the backyard with the family Akita on the day of the attack. The patient's mother found the child face down on the ground surrounded by a large amount of blood, with the Akita nearby. The patient was found to have multiple rib fractures and flail chest for which a chest tube was placed. CT scanning of the thoracic spine revealed multiple fractures of the posterior elements of T4-6 without any ongoing cord compression. MRI revealed T2 hyperintensity within the spinal cord at the level of the injury (Fig. 1). At the time of arrival to the hospital, her examination findings were consistent with a complete thoracic-level spinal cord injury. She underwent exploration of the thoracic cage wound with plating of the ribs, at which time a frank CSF leak was encountered with communication between the thecal sac and pleural cavity. A lumbar drain was placed, and this successfully stopped the CSF leak after several days of drainage. The patient had a prolonged course in the intensive care unit and eventually underwent a T4-10 posterior spinal fusion for stabilization. She did not recover any neurological function and remains paraplegic at the T-6 level. Since her hospitalization, she has required intrathecal baclofen pump placement for treatment of spasticity.

\section{Case 11}

This 9-month-old boy was attacked by the family's American Bulldog (Fig. 2). The child was playing on the floor near his mother when the dog jumped onto the child, biting him directly on the head and pinning him to the floor. The mother was able to pry the dog from the child, but immediately noted a large scalp defect and fragments of the child's skull strewn about the floor. The patient was transported by air ambulance to the emergency department. Initial examination revealed a large defect of scalp and bone over the right side of the head with active herniation of brain parenchyma out of the defect. CT scanning and CTA of the head revealed a large depressed skull fracture transversing the right sylvian fissure and transecting multiple $\mathrm{M}_{3}$ and $\mathrm{M}_{4}$ branches, many of which exhibited active extravasation. There was accompanying intraparenchymal, subdural, and intraventricular hemorrhage. The patient was taken immediately to the operating room for decompressive craniectomy and placement of an intracranial pressure monitor. During the operation he experienced cardiac arrest followed by successful resuscitation. A large amount of venous bleeding was encountered, which was controlled only by placement of nonresorbable packing material. The patient underwent multiple surgical interventions over the next several weeks to months including placement of an external ventricular drain on 3 separate occasions, removal of the intracranial packing material, debridement and washout of the wound on 2 separate occasions, and ventriculoperitoneal shunt placement with a single, subsequent revision. He developed an intracranial infection from Klebsiella and Pseudomonas spp. less than 1 week after the attack that was successfully treated with antibiotics and surgical debridement. Approximately 3 months after the initial attack, he developed a fungal infection localized to the site of injury that was treated with antifungal medications and surgical debridement of the epidural space.

The patient had a large scalp defect from the time of injury that was initially covered by a DuraMatrix-Onlay (Stryker). AlloDerm Regenerative Tissue Matrix (LifeCell Corp.) was sewn to the scalp edges to cover the dural patch and to prevent desiccation (Fig. 2F). Once the scalp edges showed granulation tissue, the AlloDerm was replaced by a Dermal Regeneration Template (Integra), which provided a framework for blood vessels and dermal skin cells to regrow into the area. Five months after the attack, the exposed dura and the sites covered with Integra were completely covered with granulation tissue. 

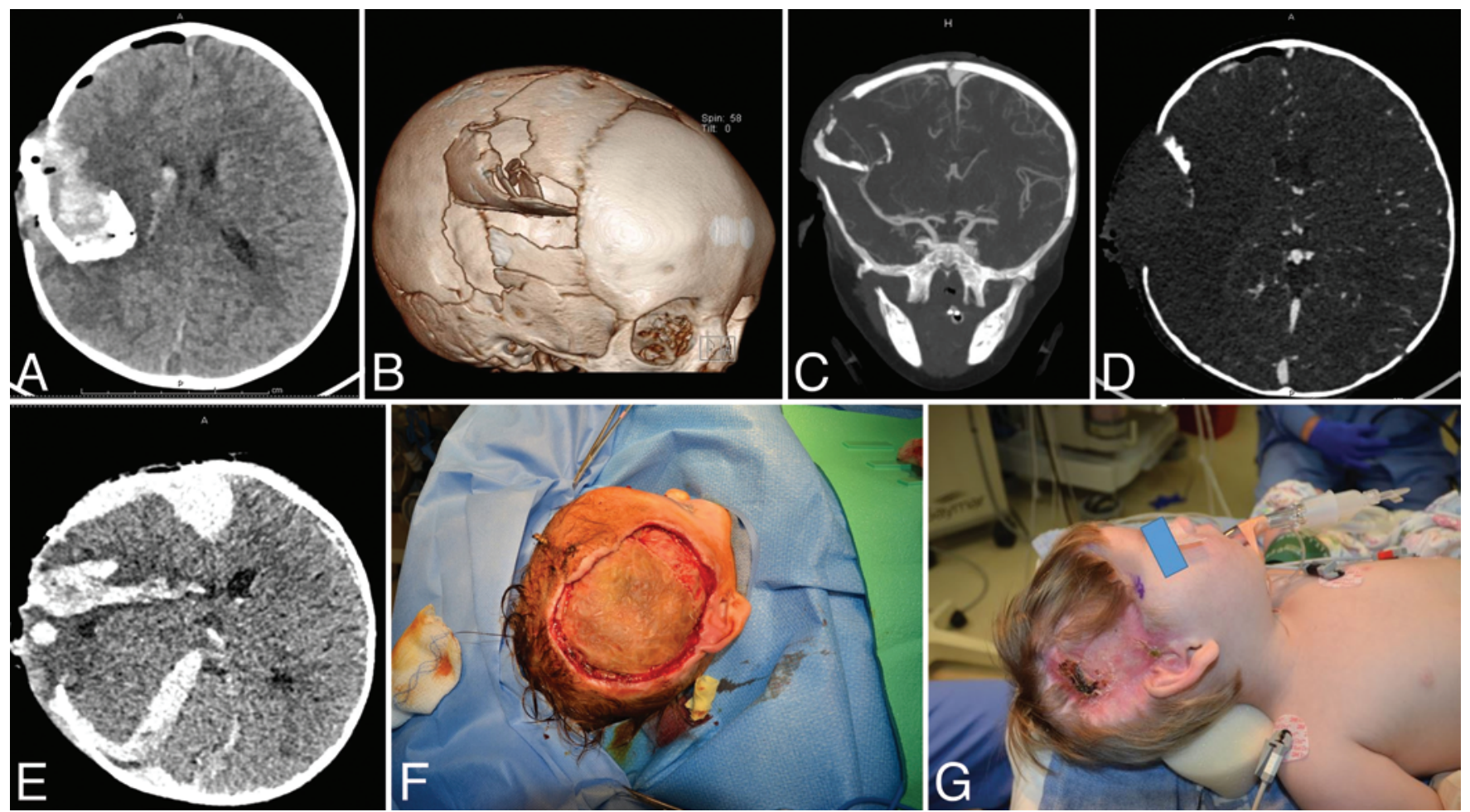

FIG. 2. Case 11. A: CT scan of the head at the time of admission of a 9-month-old boy attacked by the family's American Bulldog, showing a severely depressed skull fracture extending nearly to the lateral ventricle, with associated intracranial hemorrhage. $\mathrm{B}: 3 \mathrm{D}$ reconstruction of the initial head CT scan demonstrating the massive cranial defect within the parietal bone. C: CT angiogram of the head obtained just after the injury, showing the large depressed skull fragment transversing across several $M_{3}$ branches of the right middle cerebral artery. D: The corresponding vascular territory of the right middle cerebral artery shows a paucity of vascular filling in this axial slice of the CT angiogram. E: CT scan obtained shortly after right-sided decompressive craniectomy, showing a significant amount of brain herniation through the cranial defect as well as large subdural and intraparenchymal hematomas. During the surgery, massive venous bleeds were encountered that could only be controlled by tamponade with packing material. F: The scalp defect was initially covered with AlloDerm placed over the dural patch. G: The scalp completely healed after skin grafting. With debridement of the remaining scab, the area completely reepithelialized with no additional grafting. Figure is available in color online only.

At this point a split-thickness graft was placed over the defect with eventual complete healing of the area (Fig. 2G). When the child is older, he will likely require a free flap prior to cranioplasty. He continues to have a left hemiparesis and mild developmental delay, but is able to ambulate and communicate verbally.

\section{Case 14}

This 6-month-old boy was lying on the floor with his mother nearby when the family's American Bulldog attacked the child without provocation, biting him several times on the head (Fig. 3). He was brought to the emergency room where he was noted to have normal neurological examination findings. Head CT showed a right frontal, comminuted, depressed skull fracture with associated subarachnoid hemorrhage. One bone fragment penetrated deep into the frontal lobe, nearly reaching the lateral ventricle. He was admitted to the intensive care unit and started on prophylactic antibiotics. The scalp laceration was debrided and closed, but it was elected not to elevate the depressed skull fracture. The patient was discharged home 7 days after the initial injury. He received intravenous antibiotics for several weeks as he was felt to be at high risk for developing an intracranial infection. He recovered without sequelae and is now 4 years old with normal developmental milestones.

\section{Discussion}

We performed a retrospective review of all children sustaining dog bites to the head, face, and neck who were admitted to the emergency department of a regional Level 1 pediatric trauma center over 15 years. We found 17 cases of dog attacks on children that required a neurosurgical consultation. Attacks on females and males were nearly equal in this series, a finding contrary to that in other studies in which there is a slight preponderance to male victims. ${ }^{4,6}$ The average age of the child at the time of the attack was younger than 3 years old in this series. The majority of dog attacks in the United States and other countries occurs in children younger than 14 years.,12,16

All attacks requiring neurosurgical consultation were committed by large-breed dogs. The most common breeds involved in the attacks were German Shepherds and Akitas. Other common breeds included American Bulldogs, large mixed breeds, Labrador Retrievers, and Pit Bulls. 


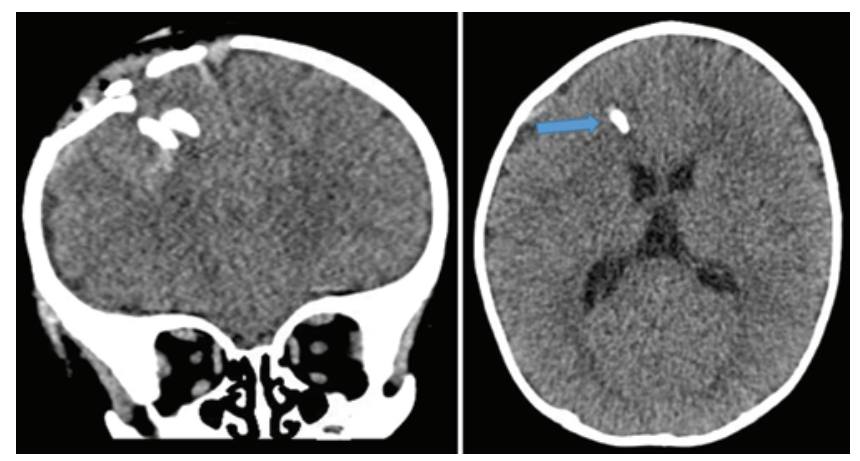

FIG. 3. Case 14. Coronal (left) and axial (right) CT scans showing a depressed, comminuted skull fracture of the right frontal bone in a 6 -month-old child after an attack by the family's American Bulldog. Note the proximity of the depressed bone fragments (arrow) to the frontal horn of the lateral ventricle. Figure is available in color online only.

According to the American Kennel Club, German Shepherds and Labrador Retrievers are among the top 5 most popular dog breeds in the Denver area (http://www.akc. org/register/top-dogs-by-city/); however, without an accurate census of the dog breed population, it is impossible to draw clear conclusions regarding the incidence of certain dog breeds to be involved in serious attacks on children. Nonetheless, previous studies have shown a "usual suspect" lineup of dog breeds guilty for attacks on children (Table 3). Pit Bull and Rottweiler are the breeds most commonly implicated in fatal dog attacks..$^{18}$ Other breeds commonly reported in serious attacks include Chow, Labrador, German Shepherd, and Great Dane.,2,4,6,7 The traits and characteristics of many of these breeds have been selected over centuries for use in hunting, flock and property protection, or fighting, which may partly explain their propensity for hostile aggression toward children. The majority of attacks were perpetrated by the family dog without witnessed provocation by the child, a finding that has been observed in other series. ${ }^{2,4,6}$ Besides breed of dog, other risk factors for an attack include dogs that are unneutered and male. ${ }^{7}$ Given the ability of large-breed dogs to swiftly inflict severe injuries on children, prevention of an attack is key. Responsible ownership, facilitated by public education, is of utmost importance and should entail the promotion of neutering/spaying of animals, and education regarding the higher risk of a serious attack with certain dog breeds. Parental supervision, though important, may not be enough, given that the majority of attacks in this series occurred in the presence of an adult, even those with catastrophic neurological injury.

As children are often playing on the ground or at eye level with many large-breed dogs when they are standing, there is a propensity for dogs to attack the head and neck. This, combined with the physical characteristics of a softer, more malleable skull in children, leads to the potential for infliction of severe injuries to the head. The strong jaw pressure of large-breed dogs along with the ability of the jaws to encompass both sides of a small child's skull leads to a high rate of depressed skull fractures. ${ }^{1,5,17,23}$ Penetrating bone fragments may cause parenchymal or vascular injury. Less dramatic skull fractures commonly involved a puncture hole in the skull ${ }^{11}$ with or without dural tear, likely caused by penetration by the dog's large canine teeth. In children younger than 1 year, dural lacerations and parenchymal injury may occur in the absence of significant injury to the skull. ${ }^{10}$ An example of this is Case 13 in which the bite was centered around the anterior fontanelle, leading to dural laceration with clinically evident CSF leakage and an underlying parenchymal injury. Lastly, large-breed dogs are capable of exerting a significant amount of blunt force to the child as well, a finding which has been shown to lead to intracranial hemorrhage. ${ }^{2}$ Carotid and vertebral artery dissection after a dog attack, as seen in the patient in Case 2, is likely a blunt force mechanism, although direct penetrating injuries to the cervical vasculature have also been described. ${ }^{15,27}$

The late detection of arterial injury in the patient in Case 2 may have led to a delay in treatment of the ICA and vertebral artery injuries. Early recognition of the vascular injury would have allowed for closer monitoring for stroke symptoms, the consideration of further diagnostics such as angiography, and potential treatment with endovascular techniques, although these modalities were much more limited when this patient presented than they are today. It is possible that the vertebral artery injury seen on cerebral angiography-but not detected on CT scanning of the neck-was present as a lower-grade injury that later progressed to complete occlusion in the absence of appropriate treatment. Modern CT angiography of the neck allows for much greater diagnostic detail than the technology available for this case.

Surgical intervention was commonly required in this series. The type of surgery varied, with local debridement, duraplasty, and elevation of depressed skull fractures being fairly common. The patient in Case 11 required multiple neurosurgical interventions, many of which had to be

TABLE 3. Characteristics of dog attacks in the literature

\begin{tabular}{lrcrcccc}
\hline \multicolumn{1}{c}{ Authors \& Year } & $\begin{array}{c}\text { No. of } \\
\text { Patients }\end{array}$ & $\begin{array}{c}\text { Injuries to } \\
\text { Head/Neck (\%) }\end{array}$ & $\begin{array}{c}\text { M/F } \\
\text { Ratio }\end{array}$ & $\begin{array}{c}\text { Mean Age of } \\
\text { Victim (yrs) }\end{array}$ & $\begin{array}{c}\text { Most Common Dog } \\
\text { Breed Involved }\end{array}$ & $\begin{array}{c}\text { Attacks by } \\
\text { Family Pet (\%) }\end{array}$ & $\begin{array}{c}\text { Required } \\
\text { Surgery (\%) }\end{array}$ \\
\hline Steen et al., 2015 & 10 & 100 & $1.5: 1$ & 2.9 & Pit Bull/St. Bernard & 80 & 50 \\
\hline Calkins et al., 2001 & 8 & 75 & $1.66: 1$ & 5.2 & Rottweiler & 50 & 100 \\
\hline Daniels et al., 2009 & 1347 & 48.7 & $1.3: 1$ & 7.28 & Pit Bull & 37 & - \\
\hline Garvey et al., 2015 & 282 & 4.6 & $1.2: 1$ & 5 & Pit Bull & 53 & 68.4 \\
\hline Present study & 17 & 94 & $0.89: 1$ & 2.5 & GS/Akita & 71 & $71^{*}$ \\
\hline
\end{tabular}

\footnotetext{
* Total number of children requiring any type of surgery; $59 \%$ required a neurosurgical procedure.
} 
undertaken in partnership with the plastic surgery team as the patient had acquired a large scalp defect from the attack. Previous studies of dog attacks in children have shown a high rate of surgical intervention, commonly for laceration repair. ${ }^{6}$ Steen et al. recently published a report on a series of 10 children with intracranial injury from dog bites, of which $50 \%$ required surgical intervention. ${ }^{22}$

The native oral flora of canines includes multiple aerobic and anaerobic bacteria such as Streptococcus, Staphylococcus, Corynebacterium, Pasteurella, and Bacteroides spp. ${ }^{8,20}$ Infections after dog bite generally occur from those bacteria found in the mouth of the canine or on the skin of the victim..$^{24}$ Most infections are multimicrobial, commonly including Pasteurella, Streptococcus, and Staphylococcus spp. ${ }^{25}$ Prophylactic antibiotic administration for dog bites is widely performed; however, strong evidence for the effectiveness of prophylactic antibiotics is lacking. ${ }^{13}$ The Infectious Diseases Society of America recommends amoxicillin and clavulanate for first-line oral, outpatient therapy; however, the duration of therapy is still not well defined. ${ }^{24}$ Despite the use of prophylactic antibiotics, intracranial infection may still occur.19 These infections may be delayed; thus, follow-up at least several weeks after the initial attack should be performed. It remains to be seen whether patients with evidence of dural penetration suffer higher rates of infection after a dog bite; however, we elected to treat any patient with direct inoculation of a dog's oral flora into the central nervous system with an aggressive regimen of prophylactic antibiotics. In this series, 15 patients received prophylactic antibiotics, and the status of 2 patients was not documented. The patient in Case 11 was diagnosed with an infection at the site of attack on 2 separate occasions, involving 3 different pathogens. This patient was particularly prone to infection, as the initial bite to the head caused a large defect of scalp, bone, and dura, thereby allowing a large amount of the intracranial content to herniate outward. The infections in this patient likely occurred due to bacterial inoculation at the time of the attack as well as contamination of the site at a later point due to the inability to completely cover the wound with native skin.

Severe neurological injury and even death from intracranial injury, though rare, has been reported..$^{2,14}$ The majority of patients in this series (82\%) did not incur any neurological deficit as a result of their injury. However, in the 3 patients who did, the injury was catastrophic. Two of these patients had injuries to more than one part of the body. Two had cardiorespiratory compromise, requiring intubation in both and cardiopulmonary resuscitation in one. These cases illustrate the importance of a thorough trauma evaluation on any child who has been attacked by a large-breed dog.

This study has several limitations. First, its retrospective study design has inherent weaknesses including an inability to analyze causality and greater potential for the introduction of bias. Plus, the descriptive nature of the statistics and lack of any control group limited any statistical analysis. Last, the management of patients' injuries, such as antibiotic administration or the need for surgical administration, was at the discretion of the treating provider, which certainly introduced variation in treatment from patient to patient.

\section{Conclusions}

In this study, large-breed dogs were responsible for all attacks on children requiring neurosurgical consultation. Most dogs were family pets with no history of prior aggression, and most of the attacks occurred at home. Neurosurgical injuries often involve the cranial vault, with depressed skull fractures being the most common injury pattern. Injury to the spinal column and cervical vasculature may also occur. A minority of patients suffer catastrophic neurological injury. Prophylactic antibiotics are commonly used, with amoxicillin-clavulanate the most common primary oral agent. Surgical intervention was required in the majority of cases in which neurosurgical consultation was warranted.

\section{References}

1. Burns R, Kusanale A, Brennan PA: Penetrating skull and brain injury due to a dog bite: a cautionary tale for the unwary. Br J Oral Maxillofac Surg 49:582-583, 2011

2. Calkins CM, Bensard DD, Partrick DA, Karrer FM: Lifethreatening dog attacks: a devastating combination of penetrating and blunt injuries. J Pediatr Surg 36:1115-1117, 2001

3. Centers for Disease Control and Prevention (CDC): Nonfatal dog bite-related injuries treated in hospital emergency departments-United States, 2001. MMWR Morb Mortal Wkly Rep 52:605-610, 2003

4. Daniels DM, Ritzi RBS, O'Neil J, Scherer LR: Analysis of nonfatal dog bites in children. J Trauma 66 (3 Suppl):S17S22, 2009

5. Froind S, Parra AS, Segal N: Delayed diagnosis of intracranial injury due to a dog bite - a case report and review of the literature. Int J Pediatr Otorhinolaryngol 77:1400-1402, 2013

6. Garvey EM, Twitchell DK, Ragar R, Egan JC, Jamshidi R: Morbidity of pediatric dog bites: a case series at a level one pediatric trauma center. J Pediatr Surg 50:343-346, 2015

7. Gershman KA, Sacks JJ, Wright JC: Which dogs bite? A case-control study of risk factors. Pediatrics 93:913-917, 1994

8. Goldstein EJ, Citron DM, Finegold SM: Role of anaerobic bacteria in bite-wound infections. Rev Infect Dis 6 (Suppl 1):S177-S183, 1984

9. Horswell BB, Chahine CJ: Dog bites of the face, head and neck in children. W V Med J 107:24-27, 2011

10. Iannelli A, Lupi G: Penetrating brain injuries from a dog bite in an infant. Pediatr Neurosurg 41:41-45, 2005

11. Mason AC, Zabel DD, Manders EK: Occult craniocerebral injuries from dog bites in young children. Ann Plast Surg 45:531-534, 2000

12. Mathews JR, Lattal KA: A behavioral analysis of dog bites to children. J Dev Behav Pediatr 15:44-52, 1994

13. Medeiros I, Saconato H: Antibiotic prophylaxis for mammalian bites. Cochrane Database Syst Rev (2):CD001738, 2001

14. Meuli M, Glarner H: Delayed cerebral infarction after dog bites: case report. J Trauma 37:848-849, 1994

15. Oshima T, Mimasaka S, Yonemitsu K, Kita K, Tsunenari S: Vertebral arterial injury due to fatal dog bites. J Forensic Leg Med 15:529-532, 2008

16. Ozanne-Smith J, Ashby K, Stathakis VZ: Dog bite and injury prevention-analysis, critical review, and research agenda. Inj Prev 7:321-326, 2001

17. Pinto FG, Tavares WM, Cardeal DD, Bor-Seng-Shu E, Andrade AF, Teixeira MJ: Craniocerebral injuries from dog bites. Arq Neuropsiquiatr 66:397-399, 2008 (Erratum in Arq Neuropsiquiatr 66:608, 2008)

18. Sacks JJ, Sinclair L, Gilchrist J, Golab GC, Lockwood 
$\mathrm{R}$ : Breeds of dogs involved in fatal human attacks in the United States between 1979 and 1998. J Am Vet Med Assoc 217:836-840, 2000

19. Santana-Montero BL, Ahumada-Mendoza H, Vaca-Ruíz MA, Castro-Sierra E, Sánchez-Herrera F, Fernández-Portilla E, et al: Cerebellar abscesses caused by dog bite: a case report Childs Nerv Syst 25:1137-1141, 2009

20. Saphir DA, Carter GR: Gingival flora of the dog with special reference to bacteria associated with bites. J Clin Microbiol 3:344-349, 1976

21. Shields LBE, Bernstein ML, Hunsaker JC III, Stewart DM: Dog bite-related fatalities: a 15-year review of Kentucky medical examiner cases. Am J Forensic Med Pathol 30:223-230, 2009

22. Steen T, Ravin K, Timmons S, Kershenovich A: Intracranial injuries from dog bites in children. Pediatr Neurosurg 50:187-195, 2015

23. Steinbok P, Flodmark O, Scheifele DW: Animal bites causing central nervous system injury in children. A report of three cases. Pediatr Neurosci 12:96-100, 1985-1986

24. Stevens DL, Bisno AL, Chambers HF, Everett ED, Dellinger $\mathrm{P}$, Goldstein EJC, et al: Practice guidelines for the diagnosis and management of skin and soft-tissue infections. Clin Infect Dis 41:1373-1406, 2005 (Erratum in Clin Infect Dis 42:1219, 2006)

25. Talan DA, Citron DM, Abrahamian FM, Moran GJ, Goldstein EJ: Bacteriologic analysis of infected dog and cat bites. N Engl J Med 340:85-92, 1999
26. Tsokos M, Byard RW, Püschel K: Extensive and mutilating craniofacial trauma involving defleshing and decapitation: unusual features of fatal dog attacks in the young. Am J Forensic Med Pathol 28:131-136, 2007

27. Varela JE, Dolich MO, Fernandez LA, Kane A, Henry R, Livingston J, et al: Combined carotid artery injury and laryngeal fracture secondary to dog bite: case report. Am Surg 66:1016-1019, 2000

\section{Disclosures}

The authors report no conflict of interest concerning the materials or methods used in this study or the findings specified in this paper.

\section{Author Contributions}

Conception and design: Kumar, O’Neill. Acquisition of data: Kumar. Analysis and interpretation of data: Kumar, O’Neill. Drafting the article: Kumar. Critically revising the article: all authors. Reviewed submitted version of manuscript: O'Neill.

\section{Correspondence}

Ramesh Kumar, Department of Neurosurgery, University of Colorado, 13123 E 16th Ave., Box 330, Aurora, CO 80045. email: ramesh.kumar@ucdenver.edu. 